\title{
Queers in the Classroom: The Role of Sexual Identity in the Academic Experiences of Gay Male Graduate Students
}

John ECKER* 1

1 Student, University of Ottawa, Canada

*Auteur(e) correspondant | Corresponding author : jecke081@uottawa.ca

Résumé :

(traduction)

Mots-clés :

Abstract:

Keywords:
Les expériences de trois étudiants masculins du cycle supérieur qui s’identifient comme homosexuels ont été explorées afin de comprendre le rôle que l'orientation sexuelle jouait dans leur vie scolaire. Grâce à des entretiens semi-structurés, les participants ont pu partager leurs expériences en tant qu'étudiants masculins gays du cycle supérieur, et les effets sur leur expérience éducative. Une approche modifiée basée sur la théorie ancrée (" grounded theory ") a servi à l'analyse des entretiens retranscrits. Trois thèmes principaux s'en sont dégagés : a) le choix de divulguer son identité sexuelle en milieu scolaire ; b) les défis rencontrés dans le cadre des interactions avec les pairs ; et c) les avantages d'être un étudiant masculin gay au cycle supérieur. Les résultats suggèrent que la gestion et l'expression de son identité sexuelle sont des processus importants qui interagissent avec plusieurs aspects de la vie des étudiants homosexuels masculins.

Hommes homosexuels, identité sexuelle, école des études supérieures, étudiants du cycle supérieur, expérience scolaire

The experiences of three self-identified gay male graduate students were explored to understand the role that sexual orientation played within their academic lives. Through semi-structured interviews, the participants were able to share their experiences of being a gay male graduate students and the effects on their educational experience. The transcribed interviews were analyzed using a modified grounded theory approach. Three main themes emerged: a) choosing to disclose sexual identity within the academic setting; b) challenges encountered when interacting with classmates; and c) benefits of being a gay male graduate student. Findings suggest that managing and expressing one's sexual identity are important processes that interact with several aspects of the life of gay male graduate students.

Gay males, sexual identity, graduate school, graduate students, academic experience 


\section{Introduction}

The literature on sexual minority (lesbian, gay, bisexual, or transgender individuals) university students is often framed in terms of challenges and homonegativity. With regards to challenges, studies have found that sexual minority students face substantial levels of harassment. Selfreported rates of verbal harassment directed at sexual minority students ranged from 65\% (Herek, 1993) to $75 \%$ (D'Augelli, 1992), and 25\% of students reported being threatened with violence (D’Augelli, 1992; Herek, 1993). Herek's (1993) sample was mostly undergraduates; however, when graduate students were extracted it was found that these students experienced lower levels of harassment. In a more recent study, Rankin (2005) reports that onethird of sexual minority undergraduate students experienced harassment within the past year. This number was slightly lower among sexual minority graduate students. Among both sexual minority undergraduate and graduate students, three-quarters viewed the campus climate as homophobic. This contrast between the incidences of harassment and the perceived campus climate demonstrates that despite a minority of sexual minority students experiencing harassment on campus, the majority of sexual minority students feel their campuses are unsupportive of sexual minorities.

The second theme within the literature involves student attitudes toward sexual minorities. It is often reported that male undergraduate (Jewell \& Morrison, 2010; Lambert, Ventura, Hall, \& Cluse-Tolar, 2006; Swank \& Raiz, 2010) and graduate (Newman, Dannenfelser, \& Benishek, 2002) students hold more negative views toward sexual minorities, yet some studies have found no gender differences (Cotten- Huston \& Waite, 2000; Korfhage, 2006). Having strong religious convictions (Cotten-Huston \& Waite, 2000; Newman et al., 2002; Rainey \& Trusty, 2007), a more conservative political alignment (Newman et al., 2002; Rainey \& Trusty, 2007), and more traditional gender role attitudes (Korfhage, 2006) were also associated with holding more negative views toward sexual minorities.

Other research has found that upper-year students (undergraduates in their third and fourth year) hold less negative views of sexual minorities than lower-year students (undergraduates in their first and second year), indicating that tolerance increases as one proceeds through university (Lambert et al., 2006); however, the views of lower-year undergraduate students on sexual minorities has improved over the years as demonstrated by a study conducted by Altemeyer (2001). The author assessed the attitudes of incoming undergraduate students every year for ten years and found a significant and positive change in more accepting attitudes toward sexual minorities.

Unfortunately, little research has been conducted to assess how sexual minority students perceive and interact within their post-secondary institutions (Longerbeam, Kurotsuchi Inkelas, Johnson \& Lee, 2007). Of the research that has been conducted, one of the themes to emerge was the challenges and benefits of disclosing one's sexual orientation. In an older study, Lopez and Chism (1993) found that undergraduate students made daily decisions about revealing their sexuality in public, particularly within the classroom. Their participants carefully assessed the classroom climate before deciding to disclose. Participants found it easier to disclose in upper-year courses, as they felt that the students were more receptive.

Stevens, Jr. (2004) investigated the experiences of gay male undergraduate students and reported that disclosure of one's sexuality led to the development of support networks. These networks, composed of other gay students or accepting heterosexual peers, provided balance to the homophobia and heterosexism experienced on campus. Participants described certain campus groups, particularly fraternity houses or athletic teams, as unpopular environments for gay males. Participants felt that these groups were hyper masculine and heterosexually focused. This sentiment was also reflected by the participants in the Lopez and Chism (1993) study.

Chur-Hansen (2004) interviewed gay and lesbian medical students in Australia. The author found that secrecy about their sexual orientation was a dominant theme among the student responses. A majority of the students were afraid of university staff finding out about their sexuality. Gossip was a second theme to emerge. The participants were worried that trusted friends would gossip about their sexuality to other classmates and faculty. Because of these fears, many students did not disclose their sexual identity.

\section{Research Question}

The current qualitative study will be primarily exploratory in nature due to the lack of empirical literature available. The main research question to be asked is: How does a gay man's sexual orientation affect the graduate school experience? It is acknowledged that this research question is rel- 
atively broad in scope. This was purposefully sought, as qualitative inquiry allows for the elaboration of research questions throughout the research process (Maxwell, 1998). A broad research question also reduces personal motives that may influence the research process. For example, the author's research serves a largely personal purpose, in that he has a strong association with the topic.

\section{Methodology}

\section{Sample}

This study was conducted as part of a class requirement. Due to the limited timeframe of the class, a small sample of three individuals was recruited. Small samples allow for cross-case comparisons and monitoring of the interview data in relation to theoretical developments, something that cannot be reasonably done with larger samples (Crouch \& McKenzie, 2006). Although a small sample size does not allow for definitive conclusions to be made, the exploratory nature of the current study does not set out to make such conclusions. Instead, exploratory research with smaller samples intends to formulate propositions, not verify them (Crouch \& McKenzie, 2006).

Purposeful sampling was the technique used to select participants. This type of sampling allows for a selection of cases that can provide the richest research data possible, since the data is not randomly sampled (MacDougall \& Fudge, 2001). There were two main considerations made with regards to the selection of the sample. Firstly, it was decided to focus exclusively on gay males due to the small sample size required for the class assignment. The experiences of lesbian, bisexual, and transgender graduate students may differ drastically from gay males and with the small sample size, representative data would be difficult to generate if the sample was not heterogeneous. Secondly, there was a decision to focus on the experiences of only graduate students since their experiences were underreported within the literature.

Convenience sampling was used for recruitment, as one of the participants was known to the author. This participant then introduced the researcher to two of his classmates. The author did not know these two individuals. Each participant was contacted and agreed to participate in the study. The objectives of the study and the procedure of the study were discussed with the participants.
Participants were gay male graduate students enrolled at a Canadian university. All were Master's students in the last year of their studies. The average age was close to 25 years.

\section{Procedure}

As this study was conducted as part of a class requirement, the professor of the class obtained ethical approval for the study in advance. Since sexual identity can be a sensitive subject, the utmost care was taken in ensuring that the collected data remained anonymous and confidential. Informed consent was acquired from each participant. During this consent process, participants were told that they were under no obligation to answer any questions that may make them feel uncomfortable and they were made aware of their right to withdraw at any time. Each participant was assigned a code and their names did not appear on any documentation.

Data collection involved the use of semi-structured interviews, with each lasting approximately thirty to forty-five minutes. All interviews took place at the author's office in his research centre. Reflexive work completed after the original interview brought forth slight modifications to the interview protocol. It was determined that some of the questions asked were leading in nature and did not facilitate a conversational type of interview. Altering protocols is a common occurrence in qualitative inquiry, as "you can change your interview questions depending on what you learned or failed to learn” (Rubin \& Rubin, 1995, p. 145).

\section{Data Analysis}

All three of the interviews were transcribed, verbatim, by the author. Data analysis techniques consistent with grounded theory (Strauss \& Corbin, 1998) were employed. The data analysis took place in stages. The first step involved the open coding of data, wherein the constant comparison technique was used. Codes were compared within each individual transcript and across all three transcripts. Seeking out disconfirming data was continuously utilized throughout the coding process in order to increase validity (Maxwell, 1998).

Following open coding, focused coding was completed. This type of coding allows for data to be synthesized and placed into meaningful categories and subcategories. The last step involved axial coding, which establishes linkages between the categories and subcategories. This type of coding is more conceptual than descriptive (Charmaz, 2006). Throughout the latter stages of coding, the use of theoreti- 
cal memos was prevalent. These memos allow for the researcher to write down his thoughts about any linkages within the data that he perceives (Marshall \& Rossman, 2011).

Reflexive work was utilized throughout the data analysis. The author's presuppositions of the experiences of gay graduate students were bracketed out prior to the beginning of analysis. The author also answered his own interview questions, which is a technique used to distance the researcher from his or her own experiences (van Heugten, 2004). As the author was conducting this research as an "insider" and a peer of his research participants, this distancing was of particular importance. Once codes were developed, the author compared them to the responses that he had provided in his own interview. This was done as a way to reintegrate himself back into the data analysis.

\section{Results}

Through analysis of the three interviews, three themes were identified: 1 ) choosing to disclose within the academic setting; 2) challenges encountered when interacting with classmates; and 3) benefits of being a gay male graduate student. The effect of sexual orientation on interpersonal relationships and managing one's identity as a sexual minority were common themes throughout the data.

\section{Choosing to disclose within the academic setting}

The participants did not place much emphasis on their own sexuality within their academic studies. Participants stated that some of their classmates were unaware of their sexual orientation, with one participant stating that those who he thought needed to know about his sexuality knew about it. It came into question whether disclosing in the classroom was possible, as evident by the following statement: "I don't know if you can actually bring it out in an academic setting...unless you want to be, 'As a gay male, I feel this". It is up to the individual to decide if they want to disclose their sexual orientation or not. One's sexual identity can also emerge passively from social settings into the academic setting. This emergence was due to the fact that individuals within the program often socialize outside of school.

Challenges encountered when interacting with classmates
The richest category to emerge from the data was the participants' interactions with their classmates. The participants had expectations that their classmates would be intelligent, mature, and professional. As one participant stated, "these people are supposed to be a cut above what I experienced previously in my undergrad". These expectations were often not actualized. Participants were surprised with the actions and words of close-minded peers. Upon hearing classmates say "that's so gay" one participant stated that "...you would almost expect that they would understand the things that they are saying and would understand the consequences of the words that they use, but they don't'.

Although professionalism existed within the program, its genuineness was questioned. On interacting with a student who was thought to be uncomfortable interacting with sexual minorities, one participant stated "they can front and pretend as if they are comfortable in a classroom setting because they have no choice". Protocols for conduct existed with social cues influencing how people acted. The participants also spoke of the gossip that could arise within their program, specifically with relation to how they identified themselves sexually.

The participants noted differences when interacting with heterosexual female and male classmates. Two participants stated that they did not think they were treated differently by either females or males; however, they were able to provide examples of males being less comfortable in their interactions. One participant stated that it was easier to interact with females as, "they don't view you as a threatening person". With males, there was greater hesitation. One participant stated "I don't think they understand what it means to be gay".

Participants often felt there was a lack of understanding of homosexuality in general by their classmates. Within academic settings, there was concern from the participants that they would be "pigeon-holed" as the "gay one." Participants did not want others to think that their opinions were one-dimensional. One participant stated "just because I have this opinion, doesn't mean that it's coming from my gay experience". They anticipated equal respect from their classmates regardless of their sexuality.

Although none of the participants reported being discriminated against, some of their classmates did show a lack of knowledge and understanding of sexual minorities. It was shared that some classmates believed that homosexuality is 
unnatural. When asked to describe the classmates that held these views, the participants stated that it was mostly an issue of political affiliation, such as being more "rightleaning" or conservative.

\section{Benefits of Being a Gay Male Graduate Student}

The last category to emerge was that of the benefits of being a gay male graduate student. The participants viewed themselves as more open-minded and better able to take the perspectives of others because of their sexual minority status. For example, they were able relate to other students of a minority status. One participant stated that a benefit was the bonds developed with female classmates and colleagues. He described that women are often "more comfortable" with gay males and are more likely to form friendships. Having other gay male students within the program was stated to be beneficial as it allowed for a sense of group camaraderie to emerge. One participant stated that it was beneficial to have that connection and to share information that others may not necessarily understand.

\section{Discussion}

This study explored the processes and experiences of three gay male graduate students. The participants all selfidentified as gay males, but they did not feel that this was a central part of their identity. This was found both in general terms and specifically within graduate school. The participants expressed fears of being "pigeon-holed" into a one -dimensional figure that is viewed predominantly in terms of their sexuality. Due to this, the participants did not always readily disclose their sexuality. This was not done for fear of harassment or discrimination but as a way to have their opinions respected based upon merit, not on their sexual orientation.

The rationale for selective disclosure differs from that experienced by the accounts of undergraduate students within the literature. Lopez and Chism (1993) report that their participants assessed the dynamic of their classroom environment before deciding to disclose their sexual identity. This assessment was completed primarily for safety and comfort. The participants within the current study did not mention any concerns of their safety in the classroom as gay males. This difference could be attributed to the dated research of the Lopez and Chism (1993), but it also provides evidence that the university environment may be dif- ferent for undergraduate and graduate students. As graduate students are typically older than undergraduates, they may feel more comfortable with their sexuality and less concerned with the reactions from others.

The participants did not report experiencing harassment or discrimination because of their sexual identity on campus or within the classroom. This follows the dissipating trend of discrimination and harassment found within the literature. There were no reported problems in interactions with professors or administrators. Fellow classmates were described as generally positive, but there were some individuals who did not agree with the "homosexual lifestyle".

These classmates did not escalate this belief into discriminatory practice, perhaps due to the protocol of social conduct that was applied within the classroom. Classmates with prejudices against sexual minorities may not have wanted to voice these opinions because homophobic speech would not have been tolerated within the classroom. This result is similar to what Jewel and Morisson (2010) report in their analysis of undergraduate students with negative attitudes towards sexual minorities. They found that these individuals were reluctant to publicly express their feelings for fear of the social repercussions that could result.

Although it was discussed that gossip did not drastically influence the graduate school experience, its existence violated the participants' expectations of professionalism within their program. Interestingly, there seemed to be greater backlash against the perpetrators of this gossip. This could be related to "straight allies" being present within the participants' program. Although this was not mentioned within the interviews, "straight allies" are heterosexuals who are supporters of sexual minority causes (Stotzer, 2009). These "straight allies" may have found the gossip to be unsupportive of their gay classmates and therefore socially reprimanded those who spread or initiated the gossip.

Participants varied in their opinions of the causes of the homonegative interactions with their classmates. Two respondents framed their classmates' behaviour in more political ideological terms. Those who were more "conservative" were more likely to express these homonegative behaviours. This finding is similar to that found in the literature (e.g., Newman et al., 2002; Rainey \& Trusty, 2007). This finding may also be somewhat influenced by the participants being enrolled in a department 
where one's political philosophy may be presented more openly than other departments.

One participant thought that the gender of his classmates was a much stronger influence than the political beliefs of his classmates. Female students were thought to be more open to sexual minority issues than male students. Some, but not all, male students had greater discomfort and were more apprehensive in interactions. This gender divide is also supported within the literature (e.g. Jewell \& Morrison, 2010; Lambert et al., 2006; Newman et al., 2002; Swank \& Raiz, 2010).

Despite the challenges that were discussed among the participants, benefits or strengths of being a gay male graduate student were also presented. Although the participants did not view their sexuality as the most defining characteristic of their personality, the ability to discuss the benefits of being gay demonstrates that they take pride in their sexuality. In the study conducted by Chur-Hansen (2004), where participants were not open about their sexuality and feared discrimination if they were to disclose, participants could not provide examples of any benefits of being a gay student and instead listed the challenges associated with it.

The results from this research can be applied to the general health and well-being of gay male graduate students. It was evident that having a social network comprised of supportive peers could help to alleviate the stress of classroom encounters with individuals that may not have had favourable attitudes towards sexual minorities. As the participants did not recount experiencing any form of discrimination on campus, it may demonstrate that the educational institution had measures and policies in place to ensure that discrimination against sexual minorities would not be tolerated on campus. Social and institutional support are therefore instrumental in promoting the well-being of sexual minority students.

Several limitations must be acknowledged within the current study. The exploration of the topic was something that could not be studied fully with interview data from only three participants. It would have been optimal to conduct more than one interview with the participants and to provide them with this document to verify its accuracy; however, time constraints did not allow for this to happen. The city in which the study was conducted may have also influenced the data since it is an urban centre. A university in a more rural location may have resulted in different responses from participants. The close relationship the author had with the participants may have also affected the questions that were posed during the interviews, as he may not have delved as deeply into certain topics as he would have with participants that were not known to him personally.

This research did not focus on the experiences of other sexual minorities, such as lesbians, bisexuals, or transgender individuals. Their experiences are important and future research should be conducted with these important populations. Racial diversity was not explored fully within this study and should also be studied in greater detail. Although this research attempted to sample from a discipline with an equal distribution of female and male students, it was still a discipline within the social sciences, which historically has a greater presence of female faculty than other disciplines. Students within more male dominated disciplines, in both enrolment and historical contexts such as science or engineering, might provide different experiences than those in the social sciences.

Despite these limitations, this study provided an understanding of the experiences of gay male graduate students. The research provided an opportunity for gay male graduate students to express their academic experiences, something that the empirical literature has not often accomplished. From the analysis of these experiences, it was found that managing one's identity as a gay male is a dynamic process that involves contextual, interpersonal, and intrapersonal variables.

\section{References}

Altemeyer, B. (2001). Changes in attitude toward homosexuals. Journal of Homosexuality, 42(2), 63-75. doi: 10.130o/Jo82v42no2_04

Charmaz, K. (2006). Coding in grounded theory practice. In K. Charmaz, Constructing Grounded Theory: A Practical Guide Through Qualitative Analysis (pp. 42-71). Thousand Oaks, CA: Sage.

Chur-Hansen, A. (2004). Experience of being gay, lesbian or bisexual at an Australian medical school: A qualitative study. International Journal of Inclusive Education, 8(3), 281-291. doi: 10.1080/1360311032000160607

Cotten-Huston, A.L., \& Waite, B.M. (2000). Antihomosexual attitudes in college students: Predictors and classroom 
involvement. Journal of Homosexuality, 38(3), 117-133.

doi: 10.1300/Jo82v38no3_07

Crouch, M. \& McKenzie, H. (2006). The logic of small samples in interview-based qualitative research. Social Science Information, 45, 483-499. doi:

10.1177/0539018406069584

D’Augelli, A.R. (1992). Lesbian and gay male undergraduates' experiences of harassment and fear on campus. Journal of Interpersonal Violence, 7(3), 383-395. doi: 10.1177/088626092007003007

Herek, G. (1993). Documenting prejudice against lesbians and gay men on campus. Journal of Homosexuality, 25(4), 15-30. doi: 10.1300/Jo82v25no4_02

Jewell, L.M., \& Morrison, M.A. (2010). "But there's a million jokes about everybody...”: Prevalence of, and reasons for, directing negative behaviours toward gay men on a Canadian university campus. Journal of Interpersonal Violence, 25(11), 2094-2112. doi: 10.1177/0886260509354499

Korfhage, B.A. (2006). Psychology graduate students' attitudes toward lesbians and gay men. Journal of Homosexuality, 51(4), 145-159. doi: 10.1300/Jo82v51no4_o8

Lambert, E.G., Ventura, L.A., Hall, D.E., \& Cluse-Tolar, T. (2006). College students' views on gay and lesbian issues: Does education make a difference? Journal of Homosexuality, 5o(4), 1-30. doi: 10.1300/Jo82v50no4_01

Longerbeam, S.D., Inkelas, K.K., Johnson, D.R., \& Lee, Z.S. (2007). Lesbian, gay, and bisexual college student experiences: An exploratory study. Journal of College Student Development, 48(2), 215-230. Retrieved from http:// www2.nau.edu/ facdev-p/TR/Longerbeam\%20article.pdf

Lopez, G., \& Chism, N. (1993). Classroom concerns of gay and lesbian students: The invisible minority. College

Teaching, 41(3), 97-103. Retrieved from http:// www.jstor.org/stable/27558599

MacDougall, C., \& Fudge, E. (2001). Planning and recruiting the sample for focus groups and in-depth interviews. Qualitative Health Research, 11, 117-126.

Marshall, C., \& Rossman, G. B. (2011). Managing, analyzing, and interpreting data. In C. Marshall \& G. B. Rossman, Designing Qualitative Research (5th Edition) (pp. 205227). Thousand Oaks, CA: Sage.
Maxwell, J. A. (1998). Designing a qualitative study. In L. Bickman \& D. J. Rog (Eds.), Handbook of Applied Social Research Methods (pp.69-100). Thousand Oaks, CA: Sage.

Newman, B. S., Dannenfelser, P. L., \& Benishek, L. (2002). Assessing beginning social work and counselling students' acceptance of lesbians and gay men. Journal of Social Work Education, 38(2), 273-288. Retrieved from http:// www.jstor.org/stable/23043866

Rainey, S., \& Trusty, J. (2007). Attitudes of Master's levelcounselling students toward gay men and lesbians. Counselling and Values, 52, 12-24.

Rankin, S. A. (2005). Campus climates for sexual minorities. New Directions for Student Services, 111, 17-23. doi: $10.1002 / \mathrm{ss} .170$

Rubin, H. J., \& Rubin, I. S. (1995). Assembling the parts: Structuring a qualitative Interview. In Qualitative Interviewing: The Art of Hearing Data (pp. 145-167). Thousand Oaks, CA: Sage.

Stevens Jr., R. A. (2004). Understanding gay identity development within the college environment. Journal of College Student Development, 45(2), 185-206. doi: 10.1353/ csd.2004.0028

Stotzer, R. L. (2009). Straight allies: Supportive attitudes toward lesbians, gay men, and bisexuals in a college sample. Sex Roles, 6o, 67-80. doi: 10.1007/s11199-008-9508-1

Strauss, A., \& Corbin, J. (1998). Basics of qualitative research: Grounded theory: Techniques and procedures for developing grounded theory (2nd ed.). Thousand Oaks, CA: Sage.

Swank, E., \& Raiz, S. (2010). Attitudes toward gays and lesbians among undergraduate social work students. Journal of Women and Social Work, 25(1), 19-29. doi: 10.1177/0886109909356058

van Heugten, K. (2004). Managing insider research: Learning from experience. Qualitative Social Work, 3(2), 203- 219. doi: 10.1177/1473325004043386 